\title{
Relationships Between Cranial Base Synchondroses and Craniofacial Development: A Review
}

\author{
Teddy Cendekiawan, Ricky W.K. Wong* and A. Bakr M. Rabie \\ Biomedical and Tissue Engineering Research Group, University of Hong Kong, Prince Philip Dental Hospital, 34 \\ Hospital Road, Sai Ying Pun, Hong Kong
}

\begin{abstract}
Synchondrosis is defined as the development of a union between two bones by the formation of either hyaline cartilage or fibro-cartilage. This paper reviews the relationship between cranial base synchondroses and craniofacial development. The cranial base synchondroses are important growth centers of the craniofacial skeleton. Their abnormalities lead to numerous growth and developmental conditions in the craniofacial region. In dentofacial orthopedics, mechanical forces are commonly applied to cranial bones for growth modification to treat such conditions. Molecular biology and genetics provide tools to investigate the molecular mechanisms, genes and transcription factors responsible for synchondrosis and craniofacial development.
\end{abstract}

Keywords: Synchondrosis, craniofacial growth.

\section{INTRODUCTION}

Cranial base synchondroses are important growth centers of the craniofacial skeleton and the last sites in the cranium to terminate growth [1-5]. Abnormalities in synchondroses are the cause of numerous growth and developmental conditions of the craniofacial region, such as Apert syndrome (1:160000 to 1:200000 live births) [6], Crouzon syndromes (1:60000 live births) [7], Pfeiffer syndromes (1:100000 live births) [8], and Down syndrome (13:10000 live births) [9]. Some abnormalities are craniosynostoses, or premature bony fusions of skull sutures, which eventually influence the life quality of affected children and their families [10]. Much effort has been made to overcome these problems. For example, in dentofacial orthopedics, mechanical forces are commonly applied to cranial bones for growth modification [11-14].

A search of Medline Ovid from 1950 identified 258 papers on synchondrosis, consisting of 188 papers written in English and 70 in other languages, such as German, French, Japanese, Italian, Polish, Czech and Russian. Most of the papers were case reports and some were experimental reports, but only a few were literature reviews. In the light of this finding, this paper reviews the literature on cranial base synchondroses, particularly the spheno-occipital synchondrosis, focusing on sources written in English either as ejournals or in printed journals or textbooks, which were hand-searched.

\section{DEFINITION}

Synchondrosis is defined as the development of a union between two bones by the formation of either hyaline cartilage or fibro-cartilage. A synchondrosis is usually temporary and exists during the growing phase until the

*Address correspondence to this author at the $2 / \mathrm{F}$, Orthodontics, Prince Philip Dental Hospital, 34 Hospital Road, Sai Ying Pun, Hong Kong; Tel: 852-28590554; Fax: 852-25593803; E-mail: fyoung@hkucc.hku.hk intervening cartilage becomes progressively thinner during skeletal maturation and ultimately becomes obliterated and converted into bone before adult life. In simple terms, a synchondrosis is a cartilaginous joint. It allows only slight movement between bones compared with the synovial joint, which has a much greater range of movement. Throughout the human body, cartilaginous joints can be found in the pubic symphysis, between the ribs and sternum, between adjacent vertebrae in the spinal column, and at the growth plates between the epiphysis and metaphysis of tubular bones. Three synchondroses are present along the midline of the cranial base: the spheno-ethmoidal synchondrosis between the sphenoid and ethmoidal bones, the intersphenoid synchondrosis between two parts of the sphenoid bone and the spheno-occipital synchondrosis between the sphenoid and basioccipital bones.

Cranial base synchondroses are regarded as important growth centers of the craniofacial skeleton, particularly the spheno-occipital synchondrosis because of its late ossification and important contribution to post-natal cranial base growth $[1,15-18]$. The spheno-ethmoidal synchondrosis terminates at 6 years of age $[15,19]$ and the intersphenoid synchondrosis ossifies immediately before birth [20]. The spheno-occipital synchondrosis seems to have a more prominent role in growth (ontogeny) of the human skull up to adult life than other midline chondral structures [19]. Synchondroseal cartilage is abundant at birth and contains a zone of proliferative and hypertrophic cells that show active growth up to 3 to 4 years of age, after which reduction in growth is observed [21].

\section{HISTOLOGICAL STRUCTURE AND GROWTH MECHANISM OF SYNCHONDROSES}

Morphologically, a synchondrosis is similar to the longbone growth plate, except that growth at the synchondrosis is not unipolar but bipolar. Indeed, the synchondrosis can be regarded as two growth plates positioned back to back so that they share a common zone of actively proliferating 
chondroblasts, or the "rest zone". The different zones of the synchondrosis mirror each other such that there is cartilage in the center and bone at each end. The intraoccipital synchondrosis is completely ossified by 5 weeks of postnatal development, whereas the intrasphenoid and sphenooccipital synchondrosis retain a small amount of cartilage into adulthood.

Specific characteristics of several functional cell zones of a synchondrosis can be easily identified (Fig. 1) [22]:

1. Zone of vascular erosion and invasion, 1 to 2 cells thick

2. Zone of chondrolacunar hypertrophy and matrix calcification, 2 to 3 cells thick

3. Zone of matrix production or matrixogenic zone, 4 to 6 cells thick

4. Zone of cellular proliferation, 4 to 6 cells thick

\section{Central zone or resting zone, 10 to 12 cells thick}

The distinct columnar organization of zones 2 to 4 is analogous to the organization of the long-bone epiphyseal plates, which are characterized structurally by bipolar epiphyseal cartilage. These zones are responsible for the growth mechanism of endochondral bone, with the central zone as the true synchondrosis. The central, or resting, zone is synonymous to the reserve zone of the growth plate and is composed of chondrocyte precursors that direct the formation and organization of a synchondrosis. The cells in the central zone are much denser and smaller than cells in any of the other layers; they are also not arranged in columns, and are surrounded by a thicker layer of cartilage matrix [23].

The proliferative zone plays a crucial role in endochondral bone formation and is the region of active cell replication [24]. In the proliferating layer, the chondrocytes are arranged in columns that are parallel to the longitudinal axis of the bone and are separated from each other by matrices containing large amounts of collagen type II. The number of cells in each column ranges from 10 to 20 , depending on the mitotic moment of the column. The more cells there are, the greater the growth rate is [25]. Furthermore, multiple mitoses can be observed in the proximal portion of each column, even though each column behaves independently [26]. Because the two daughter cells line up along the long axis of the bone when the chondrocytes divide, clones of chondrocytes are arranged in columns parallel to this axis. This spatial orientation directs growth in a specific direction and is thus responsible for the elongate shape assumed by many endochondral bones. The chondrocytes divide only in this zone of the growth plate, and the high degree of division makes the cells flat and slightly irregular in shape. The proliferating layer has a high oxygen content, and the chondrocytes store large amounts of glycogen and have a high rate of mitochondrial ATP production [27]. The matrix is synthesized in the lower half of the proliferating layer by an extensive network of

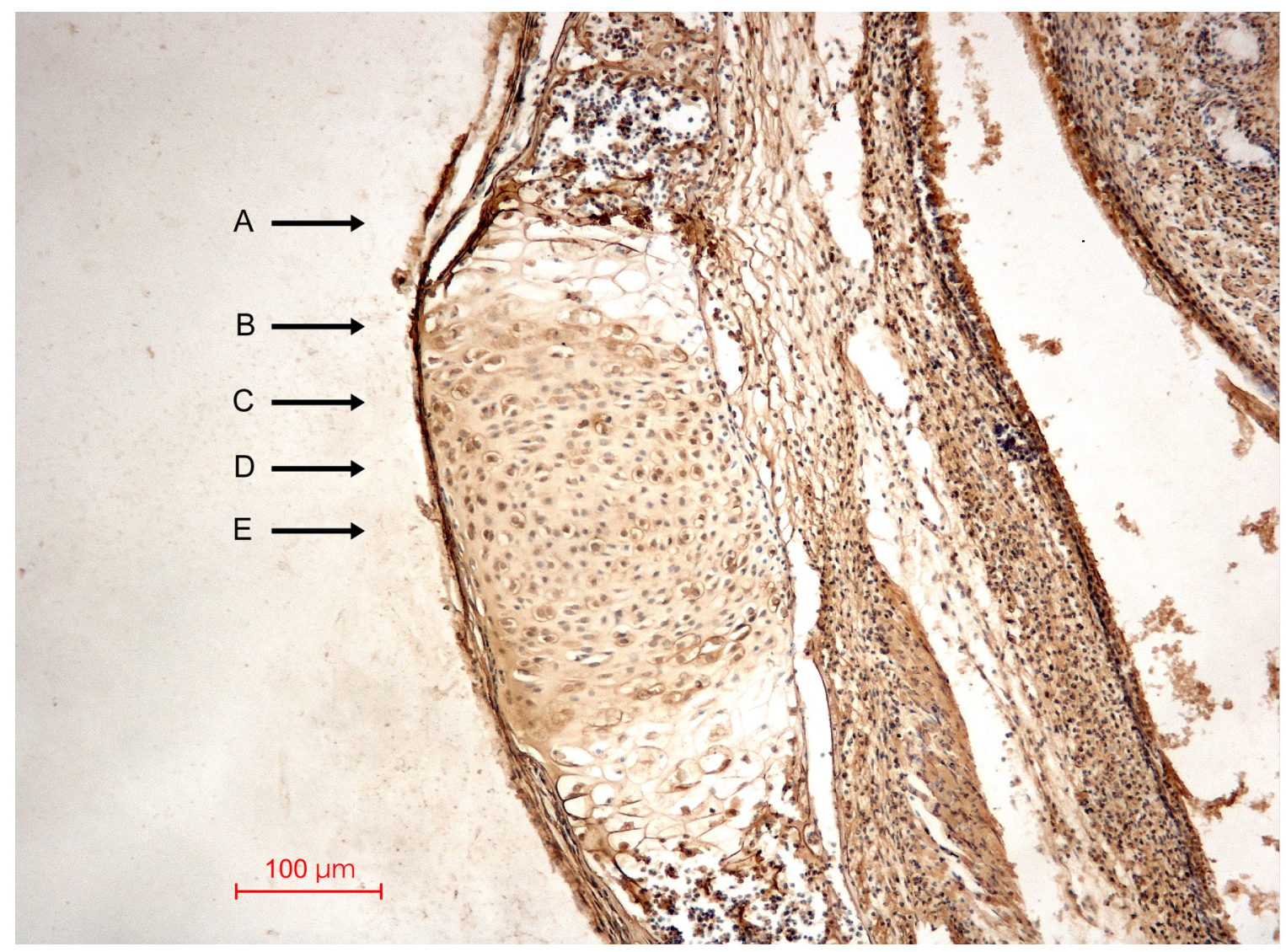

Fig. (1). Photomicrograph of a synchondrosis in neonatal mice showing different zones across one side of the synchondrosis. (A) Zone of vascular erosion and invasion. (B) Zone of chondrolacunar hypertrophy and matrix calcification. (C) Zone of matrix production or matrixogenic zone. (D) Zone of cellular proliferation. (E) Central zone or resting zone. 
chondrocytes. Ultrastructural examination has shown that these chondrocytes have large amounts of rough endoplasmic reticulum., while an autoradiographic study using tritium-labeled thymidine has revealed high rates of cell division in the three to six layers of flattened cells of the proliferative zone, with lower rates in both the resting/central zone and the prehypertrophic or matrixogenic zone [28,29].

The hypertrophic zone also plays a key role in endochondral bone formation. Hypertrophic chondrocytes are generated by terminal differentiation of the proliferative zone chondrocytes farthest from the epiphysis. The function of the hypertrophic cell layer is not only to synthesize matrix but also to cause growth by cell expansion/hypertrophy [3032]. The hypertrophic chondrocyte, by the mechanism of swelling, is actually the principal engine of longitudinal bone growth. During the differentiation process, the chondrocytes increase their intracellular volume by 5 to 10 times, a sign of major activity in the intracellular organelles and cytosol. These cells cease dividing and then enlarge, contributing substantially to the growth process [33]. The hypertrophic chondrocyte is a viable master regulatory cell with an active metabolism. It initiates ossification, which prepares the matrix for calcification and vascularization by attracting vascular and bone-cell invasion from the adjacent bone [34].

In contrast to the proliferative and hypertrophic zones, the resting zone has an unknown function. Abad and coworkers [35] suggested that resting zone cartilage makes important contributions to endochondral bone formation at the growth plate by providing stem-like cells to produce proliferative chondrocytes and producing growth plateorienting factors (GPOF), which are morphogens that control the alignment of the proliferative clones into columns parallel to the long axis of the bone. The resting zone also probably produces another type of morphogen that is responsible for inhibiting terminal differentiation of the nearby proliferative zone and thus the organization of the growth plate into distinct zones of proliferation and hypertrophy.

\section{EVOLUTIONARY SIGNIFICANCE OF CRANIAL BASE IN CRANIOFACIAL DEVELOPMENT}

The cranial base has been an interesting subject of research owing to its importance in integrated craniofacial development and growth. It is the most complex structure of the human skeleton and its main function is to protect and support the brain. The cranial base is also the first region of the skull to reach adult size and is the structural foundation of many aspects of the craniofacial architecture [36]. In addition, it also connects with the rest of the body, articulates with the vertebral column and the mandible, provides conduits for all the vital neural and circulatory connections between the brain and the face and neck, houses and connects the sense organs in the skull and forms the roof of the nasopharynx. The shape of the cranial base is therefore a multifactorial product of numerous phylogenetic, developmental and functional interactions [37, 38].

Although the cranial base, vault and face derive from embryologically distinct regions (basicranium, neurocranium and splanchnocranium), the cranial base region grows in a morphologically integrated manner through numerous developmental and functional interactions [39-41]. These interactions occur as a result of many morphogenetic (e.g., neural) and functional (e.g., masticatory, respiratory) stimuli, but the role of the cranial base in influencing overall cranial shape merits special consideration. The cranial base is derived from the chondrocranium, which serves as a growth plate, and is later replaced by bone through endochondral ossification. The chondrocranium is essentially a structural template within and around which the bony cranial base is constructed [42]. Any cartilage remaining between the bones in the form of synchondroses acts as a growth center in a similar way to the epiphyseal plates of the long bones. By the end of adolescent growth, the cranial base synchondroses have completely ossified and longitudinal growth has finished. Any interference that causes early or late ossification will result in shortening or lengthening of the cranial base, respectively, leading to serious consequences in craniofacial development [22].

\section{BIOLOGICAL BASIS OF CRANIAL BASE SYNCHONDROSES}

Information on the cartilaginous joint in the cranial base is limited, probably as a result of general acceptance that basal synchondroses are the same as the epiphyseal plates of the long bones [43]. Both share the same internal morphological features, as well as roles in endochondral bone growth [44]. In the postnatal period, endochondral ossification of the cranial base synchondroses contributes to the expansion of the ossification centers and growth of the cranial base. Therefore, cranial base synchondroses are analogous structures to growth plates of the long bones, in that they allow for the rapid endochondral growth of the bone and eventually close when the bone reaches its final size. Typical long-bone growth cartilage has been defined as a simple proliferating system that exhibits a linear mathematical relationship between cell division and bone growth [45]. Although the overall development of cranial base synchondroses has received less attention than that of long-bone growth plates, many genes have been identified that have proven to be fundamental in the development of the craniofacial complex [46].

\section{EMBRYOLOGICAL DEVELOPMENT OF CRANIAL BASE SYNCHONDROSES}

The cranial base has a distinct pattern of morphogenesis. The anterior cranial base is derived from neural crest mesoderm, which is also responsible for the growth of facial bone. In contrast, the posterior cranial base is developed from paraxial mesoderm. The cranial base develops from a cartilaginous template that is replaced by bone through the process of endochondral ossification. The cranial base is initially condensed, as individual elements. Pairs of templates, from caudal to rostral regions, are composed of sclerotome cartilage, parachordal cartilage (precursor of the basioccipital bone), hypophyseal cartilage (precursor of the basisphenoid), presphenoid cartilage (precursor to the sphenoid body anterior to the tubeculum sellae and chiasmatic sulcus), orbitosphenoid (precursor of anterior clinoids and lesser wing of the sphenoid), alisphenoid cartilage (precursor of greater wing of sphenoid) and mesethmoid cartilage. Ossification progresses in an orderly pattern from the posterior to the anterior and finally fuses into a single, irregular and much-perforated base plate, 
known as the chondrocranium [47]. The chondrocranium then undergoes further progressive ossification. Large areas of the cranial base remain cartilaginous throughout early fetal life, while many cartilages persist into the third trimester and postnatal life in humans [10].

Histological studies indicate that at least the sphenooccipital synchondrosis contains cartilaginous canals through which blood vessels travel, in addition to connective tissue elements, probably for the purpose of bringing nutrients and other supplies to the cell [48]. Several in vivo studies have been designed to investigate the development of cranial base synchondroses in using mice fetuses [49-51]. The basioccipital ossification center was the first to form, starting at 14 days post coitum (dpc), followed by the paired exoccipitals and basisphenoid. The presumptive sphenooccipital synchondrosis was found at $15 \mathrm{dpc}$; by $16 \mathrm{dpc}$, the perichondrium around the cranial base segments was interrupted at sites where synchondroses were forming. The presphenoid formed between 16 and $17 \mathrm{dpc}$. On $18 \mathrm{dpc}$, the entire presumptive cranial base was cartilaginous, and there was marked hypertrophy of chondrocytes and their lacunae in the areas of impeding basioccipital, basisphenoid and presphenoid bone formation. Cellular hypertrophy was the most advanced in the basisphenoid region, confirming the caudal-rostral sequence of cartilage maturation [52]. Throughout the first week of postnatal development, growth and ossification of the cranial base accelerated and the otic capsule ossified rapidly. By the fourth day after birth, the basioccipital-basisphenoid and basisphenoid-presphenoid synchondrosis had reached full development, in analogy to mirror-image epiphyses [49].

\section{DIFFERENTIAL GROWTH IN THE CRANIAL BASE SYNCHONDROSES}

There is no reason why growth in the zones on either side of the growth center should be the same. In human fetuses, more bone deposition occurs on the ethmoid at the sphenoethmoidal synchondrosis and on the occipital bone at the spheno-occipital junction. The sphenoid bone, therefore, shows less growth anteriorly and posteriorly. The increasing sella-foramen cecum distance after 2 years of age could mean, however, that the front part of the sphenoid grows faster postnatally than the ethmoid, and continues growing after the ethmoid has ceased [15] and the constancy of sellabasioccipital synchondrosal distance could imply a continuing preponderance of growth on the basiocciput [53]. Enlow [54] suggested that growth may occur at different rates and to different extents on opposite sides of the plate, such that in the spheno-occipital synchondrosis, the greater part of this lengthening occurs on the occipital side. It has been argued that these observations are better explained by posterior drift of the sella rather than by inequalities of synchondrosal growth. Melsen [55] did not find any asymmetry in histological examinations of the human postmortem material. Hoyte [56] studied the basicranial synchondroses in pigs and rabbits, by injecting live animals with alizarin red and sacrificing them at different intervals; the results demonstrated that growth in the basiscranial synchondroses is symmetric at each site but vary in patterned sequence between sites. Experiments using [ $\left.{ }^{3} \mathrm{H}\right]$-thymidine radioisotope labeling in growing rats found a caudo-rostral gradient of growth rates in the cranial base cartilages, with the highest rates in the basioccipital and lowest in the rostral edge of the presphenoid. In other words, the posterior part of the spheno-occipital synchondrosis has a greater amount of bone formation in its inferior part than its superior part, which leads to angular changes in the cranial base $[45,46$, 57].

\section{CRANIAL BASE SYNCHONDROSES AS GROWTH CENTERS}

An area of hypothetical debate concerns synchondrosis growth capability, and whether it is independent from or dependent on other factors. As a remnant from the fetal chondrocranium, it should be an active and expansive growth center owing to its tissue separating power. Scott [58] hypothesized that cranial synchondroses by virtue of their interstitial growth, turgidity and resistance to deforming forces can separate growing bones at sutures, just as the brain or an eyeball can. On the other hand, others [27, 59] have suggested that cranial base synchondroses do not possess a growth potential of their own and are just show a mechanically obligatory response to the growth of other organs, such as the brain, and to the growth of organ spaces, such as the oral and nasopharyngeal spaces. According to this view, the growth of the craniofacial skeleton occurs as a secondary or adaptive response to its functional matrix. In the living body, load or muscular activity serves as an extracellular stimulus that is transmitted to cells and modulates their genetic growth and differentiation, leading to what is known as the functional matrix hypothesis [60].

In order to test these hypotheses, many transplantimplants studies have been performed. Petrovic and Charlier [61] showed that chondrogenesis continued in 8-day-old explants of the spheno-occipital synchondrosis of the rat. Servoss [62] used $\left[{ }^{3} \mathrm{H}\right]$-thymidine labeling in vivo and in vitro in mice, and found that in vitro spheno-occipital synchondrosis not only continued to grow, but did so at a rate comparable to that of the in vivo counterparts. Kuroda et al. [63], repeating similar experiments in rabbits, noted that the spheno-occipital synchondrosis maintained it structure and grew independently, but less than in vivo. These experiments indicate that cranial base synchondroses are endowed with an independent growth potential and are comparable to epiphyseal plates and the costochondral junction with regards their tissue-separating capacity [64, $65]$. The independent growth potential of synchondroses [10] are also evident from the observation that their growth continues for a longer duration than that of the brain, which means the growth of the cranial base and the brain is not closely interdependent $[19,66]$. The studies overall suggest that synchondroses are genetically coded in craniofacial growth and will develop even in the absence of functional activity. However, skeletal growth and the preservation of normal structure are modulated by environmental (epigenetic) factors, such as mechanical force, hormones and other growth factors.

\section{TIME OF CLOSURE OF THE SPHENO-OCCIPITAL SYNCHONDROSIS}

Controversies have arisen with regard to the closure time of the spheno-occipital synchondrosis [34, 67, 68]. Ford [69] investigated human dry skulls and first reported that the closure time of the spheno-occipital synchondrosis occurred 
late in the growth period between 20 and 25 years or between 17 and 20 years. A radiographic study by Irwin [70] and a tomographic study by Powell and Brodie [71] led to suggestions that incipient closure may already be discerned at the beginning of puberty. Melsen [4] reported that closure had taken place in the interval between eruption of the second and third molars. Computed tomography of the spheno-occipital synchondrosis showed signs of early fusion by age 8 years of age; the age of closure was 16 years in girls and 18 years in boys [72]. On the other hand, in postmortem histologic and micro-radiographic studies of the sphenooccipital synchondrosis, Ingervall and Thilander observed closure as the appearance of bony bridges and demonstrated that the average age of closure in females is around 14 years and that the spheno-occipital synchondrosis is never completely open in many girls older than 13 years and 9 months; the corresponding age for the boys is 16 years [3, 21].

The initial establishment of an osseous bridge between the adjoining bones in humans was investigated by Melsen [55] with human autopsy materials: the process occurs between the pubertal growth maximum and the cessation of sutural growth, which corresponds to the result from Thilander and Ingervall [21]. Latham [73] noted a rapid linear increase of the basioccipital length until the age of 9 years, the beginning of a plateau at about 10 years and then another, but very slow, increase until 18 years, indicating that there is a sequence of slower growth in the synchondrosis between 8 and 11 years. Bony bridges first appear by about 12 years (females) and 13 years (males), and synostosis (all cartilage replaced by bone) takes place by the age of 16 to 17 years.

\section{ROLE OF SYNCHONDROSES IN GROWTH}

The cranial base forms the platform to which the rest of the skull grows and attaches. It provides and protects the crucial foramina through which the brain connects the face and the rest of the body [24]. As the basicranium grows, it elongates and flexes in the spheno-ethmoid, mid-sphenoid, and spheno-occipital synchondrosis [19]. Increases in basicranial breadth and length also occur in sutures (e.g., the occipito-mastoid), and the endocranial fossae of the basicranium deepens through drift, during which bone is resorbed and deposited along the superior and inferior surfaces, respectively [74]. This integrated growth occurs through many mechanisms, the most important of which are sutural expansion, synchondroseal deposition, drift and flexion. As the brain expands, it generates tension along the endocranial surface of the neurocranial cavity, thereby activating osteoblast deposition within the intra-sutural periosteum throughout the upper portion of the vault, as well as drifting in the lower portions of the vault and cranial base and endochondral growth within certain synchondroses [23, 75].

In humans, facial growth is about $95 \%$ completed by 16 to 18 years, at least 10 years after the majority of the neurobasicranial complex has reached adult size [76]. The basicranium and neurocranium, however, may have some influence on the growth of certain facial dimensions because the upper face articulates with the anterior cranial base and the anterior cranial fossa, while the mid-face articulates with the middle cranial fossa. In particular, the upper and middle portions of the face in humans grow primarily by lateral drift and anterior displacement around the ethmoid and in front of the sphenoid $[74,77]$.

\section{SYNCHONDROSIS AND CRANIAL BASE ANGLE}

Cranial base flexion is a unique cranial feature of modern human beings and also a reflection of brain evolution. Compared with the cranial of quadrupeds, the cranial base angle in humans is relatively small. This difference is believed to be mainly due to the upright posture of humans and the increase in brain volume as well as frontal positioning of the eyes [29]. Fusion along the sphenooccipital synchondrosis is believed to be responsible for cranial base flexion, which develops in concert with the development of the upper airway and the ability to vocalize $[78,79]$. During development, the anterior and posterior cranial base flexes at the sella turcica in the middle sagittal plane and thus constitutes an angle in the cranial base, termed the cranial base angle or saddle angle [10].

There are two well-known ontogenic models regarding cranial base flexion. Enlow [80] proposed that cranial base flexion during human prenatal and postnatal ontogeny is due to increased brain growth, relative to slower growth of the midline basicranium. This view is consistent with human fetal studies showing that growth along the cranial base is significantly slower than in other parts of the skull [81] and that fetal brain growth is markedly rapid at the same time [82]. Taken together, these findings imply that brain size increases relatively during human fetal life. The other ontogenic model, proposed by Ross and Ravosa and known as general spatial-packing, suggests that increases in brain size (volume) relative to length of the midline cranial base create a spatial packing problem that drives cranial base flexion and coronal reorientation of the petrous bones [83]. These spatial-packing hypotheses have been substantiated by numerous studies but not by others, owing to a basicranium that is less flexed than expected in the modern human brain $[23,84]$. The alternative explanation to this problem is that the cranial base flexion is probably an intrinsic feature of human beings that is predominantly genetically determined. However, this hypothesis has not yet been supported by research [10].

A cranial base angle is already established in the chondrocranium between the prechordal and parachordal region of the cranial base in the human fetus. It has been generally presumed that the base flattens in the early stages of development by an increasing angle between the prechordal and parachordal portions and that this process later continues between the ossified part of the basicranium [85]. On the other hand, Diewert found little change during 7 weeks and 10 weeks in human cranial base angulations, while the head lifted up and back and the face developed. Thus, the cranial base angle is similar to that in later prenatal and postnatal stages, suggesting that distinctively human patterns develop early in the embryonic period [86].

Björk [1] reported that the cranial base angle gradually bends in the first years of childhood up to about 10 years, but others have shown that bending probably happens earlier in life, perhaps by 5 to 6 years [87] or even 2 to 3 years [88]. Differences in these measurements probably relate to 
different baseline measurements and, perhaps much more importantly, also the internal aspect of the cranial base, which remains stable from early childhood onwards [29].

The cranial base angle (Fig. 2) is measured at three points antero-posteriorly and can be easily identified from cephalometric images; the most commonly used cephalometric landmarks are the nasion, sella turcica and basion. This measurement consists of two legs. The anterior leg, where the maxilla is attached, extends from the sella turcica $(\mathrm{S})$ to the frontal-nasal suture $(\mathrm{N})$. The posterior leg, where the mandible is attached, extends from the sella turcica $(\mathrm{S})$ to the anterior border of the foramen magnum, defined as the basion (Ba). Therefore, any change in the cranial base angle can affect the relationships of the maxilla and mandible and influence the type of malocclusion. The posterior leg $(\mathrm{BaS})$ of the cranial base angle $(\mathrm{BaSN})$ may be tipped anteriorly or posteriorly, whereas the anterior leg (SN) may also be tipped up or down anteriorly by variation in either $\mathrm{S}$ or $\mathrm{N}$ vertically. Furthermore, variable lengths may compensate for any cranial deflection, such as an acute posterior leg that places the mandible forward, and this action can be negated by a long posterior leg that places both the basion and mandible posteriorly and vice versa [89].

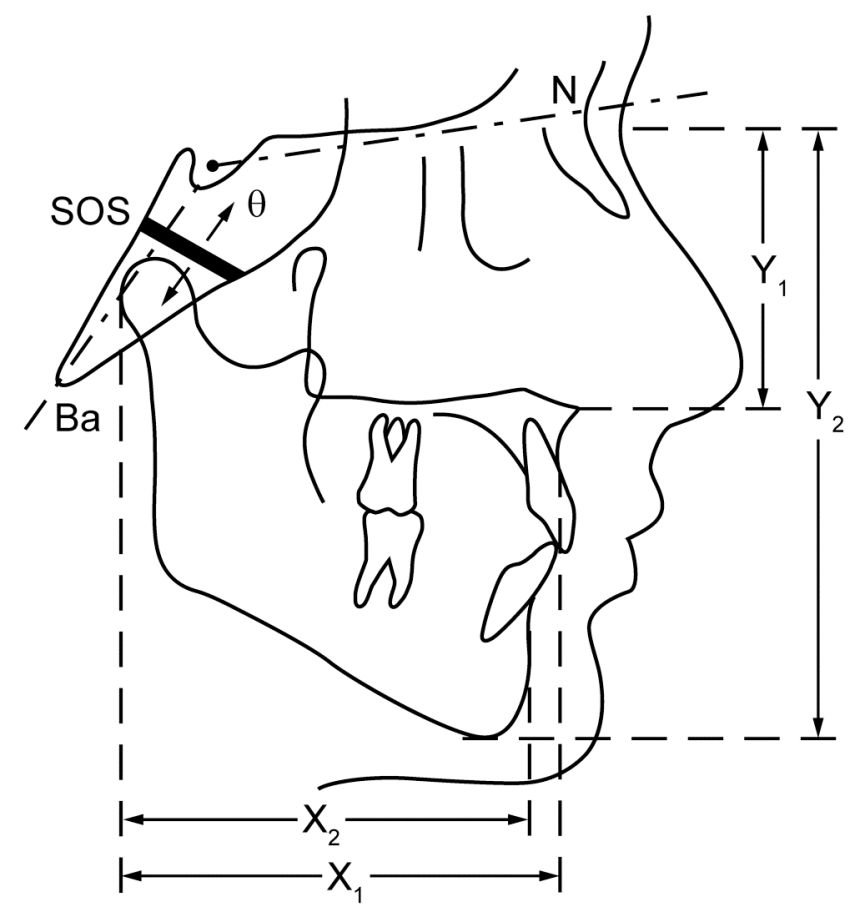

Fig. (2). Diagram showing the cranial base angle $(\theta)$, the synchondrosis (SOS) and the jaw relationship. The growth in SOS affects $\theta$ and the relative jaw positions $\mathrm{x}_{1}, \mathrm{x}_{2}$ horizontally and $\mathrm{y}_{1}, \mathrm{y}_{2}$ vertically. If $\theta$ is small, the mandible is relatively more anterior with the maxilla. Conversely, if $\theta$ is large, the mandible is relatively more posterior with the maxilla.

The posterior cranial base can grow sagittally under the aegis of the spheno-occipital synchondrosis. In contrast, the anterior cranial basis is restricted by the sphenoethmoidal and ethmoidofrontal sutures. Since the sutural growth of the anterior cranial base is complete around 8 years, the distance $\mathrm{SN}$ continues to increase for years after, but only as a result of apposition on the frontal bone [18]. As a consequence of this early completion, the anterior cranial base has been used wholly or in part as a reference in a number of cephalometric analyses. It is assumed that through ramification of sutures that link the cranial base, there is a close interrelationship between the calvarium and some facial growth. In particular, the spheno-occipital synchondrosis becomes a focus or pivot point for craniofacial growth [90].

The correlation between the cranial base angle and orthodontics was noticed and described in 1948 followed by Björk, Moss and Rickets in 1955 [91]. The assessment of orthodontic anteroposterior skeletal discrepancy of the jaws and arches should also account for the role of the cranial base [92]. The relationship of the cranial base with jaw position and classification of malocclusion has subsequently been examined extensively. Scott [93] further proposed one of the main factors that influence facial prognathism is the opening of the cranial base angle. This angle has a large individual variation, with a $5^{\circ}$ standard deviation, and is markedly decreased in value from birth until the first year. It is also considered one of the craniofacial constants as it changes little during growth from 5 to 15 years $[87,94,95]$. Smaller linear and angular dimensions have been shown in class III patients, whereas class II subjects demonstrate an increased cranial base angle that leads to a more posterior position of the mandible [92, 96, 97]. The anterior cranial base and the middle cranial fossa have also been reported to be longer in individuals with class II malocclusion [98].

However, many studies have shown that the etiological relationship between the cranial base flexion and the type of malocclusion is not well supported $[89,99,100]$. It therefore appears that the cranial base angle is not a pivotal factor in determining malocclusion. Rather, the differential growth pattern and direction between the anterior cranial base and posterior cranial base imply that length and inclination of the cranial base are controlling factors of jaw position. Abnormalities of the posterior cranial base are related to mandibular prognathism, and those of the anterior cranial base to retrusive maxilla. These relationships are probably explained by the glenoid fossa's location in the posterior cranial base; an elongated cranial base would bring the glenoid fossa back and the mandible with it [1, 93]. A Norwegian study has recently demonstrated differential growth between the anterior and posterior cranial base: in the male group, the growth curve of the anterior cranial base flattened out after 18 years but the posterior part increased until 21 years; no such difference was detected in the female group, where both growth curves flattened out after 15 years [101].

Other cephalometric characteristics resulting from skeletal type might influence the sagittal jaw position and relationship. For example, the flattening of the saddle angle is associated with a decrease of the posterior cranial base angle N-Ba-S, an elongation of the posterior part of the cranial base at Ba-point, and an enlarged distance N-Ar, all favoring an increased sagittal discrepancy of the jaws [91, 94]. A compensating mechanism associated with cranial base flexure was first described by Anderson and Popovich [102] in a study showing that the angle between the posterior cranial base and the ramus of the mandible closes in a highly correlated way to compensate for the opening of the cranial base flexure. This phenomenon tends to maintain the angle between the ramus and the anterior cranial base. Therefore, 
with a more obtuse cranial base angle, the mandible swings only slightly down and forward [101].

\section{ABNORMALITIES IN GROWTH AND DEVELOPMENT}

The spheno-occipital synchondrosis is an important link between the development of the cranial vault and that of the facial skeleton $[1,16,26]$. Premature growth arrest of the cranial base is widely regarded as the primary abnormality in syndromic forms of craniosynostosis [103]. In Klinefelter syndrome and Williams syndrome, the major craniofacial changes are located in the cranial base [104, 105]. In Cretinism syndrome, Turner syndrome [106] and Down's syndrome [107], the craniofacial structure is characterized by a short retrognathic face owing to reduced cranial base length and increased angulations. In complete clefts of lip and palate, cranial base deviations in dimension and shape have been widely described. The data indicate that cleft lip and palate are not isolated malformations localized to the jaws, but malformations that also involve the cartilaginous cranial base $[108,109]$.

\section{RECENT ADVANCEMENTS IN CRANIAL BASE RESEARCH}

Significant advances in the study of craniofacial development have revealed the genetic and environmental basis of numerous craniofacial malformations, some of which do not even appear to be genetic in origin. This finding significantly deepens our understanding toward the fundamental principles of development, how genes regulate cell activity and thus mechanisms of determining the pattern and form of the craniofacial complex. Without the knowledge of gene activity and signaling transduction pathways, the elucidation of mechanisms that control development would be impossible.

Revelations of fibroblast growth factor receptor (FGFR), Sonic Hedgehog (Shh), SOX 9 and Cbfal genes are some examples of the genes that have been found to play critical roles in craniofacial development. SOX 9 has been found to be a master transcriptional factor that regulates early differentiation of mesenchymal cells into the chondrocyte lineage [110]. The absence of SOX 9 results in a severe skeletal dwarfism known as campomelic dysplasia [111]. Cbfa1/run2/Osf2 serves as the earliest transcriptional regulator of osteoblast differentiation and can be considered to be the central regulator of intramembranous ossification [112]. Mutations involving Cbfal result in cleidocranial dysplasia in humans [5]. Shh, a member of the vertebrate Hedgehog gene family, plays an important role in establishing craniofacial midline structures and in regulating cranial suture development [113]. Shh is the most commonly identified single-gene defect causing human holoprosencephaly [114]. Mutations in genes encoding FGFRs have been identified as causes of Apert syndrome, Crouzon syndromes and Pfeiffer syndromes [5]. As for environmental effects, the use of an organ culture technique has revealed that synchondrosis is responsive to tensile mechanical stress and increased expression of various factors related to growth stimulation [115-117]. This series of studies was the first to show that growth across the synchondrosis can be modified mechanically.

\section{CONCLUSION}

Cranial base synchondroses, with their unique bipolar growth, are a fundamental part of craniofacial development. Abnormalities in their development have serious consequences because of their position and growth in the craniofacial complex. Molecular biology and genetics provide tools to further investigate the molecular mechanisms, genes and transcription factors responsible for synchondrosis and craniofacial development.

\section{REFERENCES}

[1] Bjork A. Cranial base development. Am J Orthod 1955; 41: 199255 .

[2] Dorenbos J. In vivo cerebral implantation of the anterior and posterior halves of the spheno-occipital synchondrosis in rats. Arch Oral Biol 1972; 17: 1067-72.

[3] Ingervall B, Thilander B. The human spheno-occipital synchondrosis. I. The time of closure appraised macroscopically. Acta Odont Scand 1972; 30: 349-56.

[4] Melsen B. Time of closure of the spheno-occipital synchondrosis determined on dry skulls. A radiographic craniometric study. Acta Odont Scand 1969; 27: 73-90.

[5] Rice DP, Rice R, Thesleff I. Fgfr mRNA isoforms in craniofacial bone development. Bone 2003; 33: 14-27.

[6] Kaplan, LC. Clinical assessment and multispecialty management of Apert syndrome. Clin Plast Surg 1991; 18 (2): 217-25.

[7] Cohen MM Jr, Kreiborg S. Birth prevalence studies of the Crouzon syndrome: comparison of direct and indirect methods. Clin Genet 1992; 41(1): 12-5.

[8] Vogels A, Fryns JP. Pfeiffer syndrome. Orphanet J Rare Dis 2006; 1: 19.

[9] Canfield MA, Honein MA, Yuskiv N, et al. National estimates and race/ethnic-specific variation of selected birth defects in the United States, 1999-2001. Birth Defects Res A. 2006; 76(11): 747-56.

[10] Nie X. Cranial base in craniofacial development: developmental features, influence on facial growth, anomaly, and molecular basis. Acta Odonto Scand 2005; 63: 127-35.

[11] Copray JC, Jansen HW, Duterloo HS. Effects of compressive forces on proliferation and matrix synthesis in mandibular condylar cartilage of the rat in vitro. Arch Oral Biol 1985; 30: 299-304.

[12] Forriol F, Shapiro F. Bone development: interaction of molecular components and biophysical forces. Clin Orthop Relat Res 2005: 14-33.

[13] Hickory WB, Nanda R. Effect of tensile force magnitude on release of cranial suture cells into S phase. Am J Orthod Dentofac Orthop 1987; 91: 328-34.

[14] Simon MR. The effect of dynamic loading on the growth of epiphyseal cartilage in the rat. Acta Anat (Basel) 1978; 102: 17683.

[15] Ford E. Growth of the human cranial base. Am J Orthod 1958; 44: 498-506.

[16] Koski K. Some aspect of the growth of the cranial base and upper face. Odont. Tidskr 1960; 68: 344-58.

[17] Scott JH. The growth of the human skull. J Dent Ass S fr 1958b; 13: 133 .

[18] Stramrud L. External and internal cranial base. A cross sectional study of the growth and association in form. Acta Odonto Scand 1959; 17: 239-66.

[19] Scott JH. The cranial base. Am J Phys Antropol 1958a; 16: 319-48.

[20] Hayashi I. Morphological relationship between the cranial base and dentofacial complex obtained by reconstructive computer tomographic images. Eur J Orthod 2003; 25: 385-91.

[21] Thilander B, Ingervall B. The human spheno-occipital synchondrosis. II. A histological and microradiographic study of its growth. Acta Odonto Scand 1973; 31: 323-34.

[22] Dixon AD, Hoyte DAN, Ronning O. Fundamentals of craniofacial growth. Boca Raton: CRC Press 1997.

[23] Abad V, Meyers JL, Weise M, et al. The role of the resting zone in growth plate chondrogenesis. Endocrinology 2002; 143: 1851-7.

[24] Kember NF, Walker KV. Control of bone growth in rats. Nature 1971; 229: 428-9. 
[25] Trueta J, Trias A. The vascular contribution to osteogenesis. IV. The effect of pressure upon the epiphysial cartilage of the rabbit. J Bone Joint Surg Br 1961; 43-B: 800-13.

[26] Rigal WM. The Use of Tritiated Thymidine in Studies of Chondrogenesis. Oxford: Blackwell Science Publications 1962.

[27] Brighton CT, Heppenstall RB. Oxygen tension of the epiphyseal plate distal to an arteriovenous fistula. Clinl Orthop Relat Res 1971; 80: 167-73

[28] Roberts GJ, Blackwood HJ. Growth of the cartilages of the midline cranial base: an autoradiographic study using tritium labelled thymidine. J Anat 1984; 138: 525-35.

[29] Roberts GJ, Blackwood HJ. Growth of the cartilages of the midline cranial base of the Wistar rat: an autoradiographic study using 35S-sulphate. Eur J Orthod 1991; 13: 75-80.

[30] Buckwalter JA, Mower D, Ungar R, Schaeffer J, Ginsberg B. Morphometric analysis of chondrocyte hypertrophy. J Bone Joint Surg Am 1986; 68: 243-55.

[31] Cowell HR, Hunziker EB, Rosenberg L. The role of hypertrophic chondrocytes in endochondral ossification and in the development of secondary centers of ossification. J Bone Joint Surg Am 1987; 69: 159-61.

[32] Gerstenfeld LC, Shapiro FD. Expression of bone-specific genes by hypertrophic chondrocytes: implication of the complex functions of the hypertrophic chondrocyte during endochondral bone development. J Cell Biochem 1996; 62: 1-9.

[33] Breur GJ, Van Enkevort BA, Farnum CE, Wilsman NJ. Linear relationship between the volume of hypertrophic chondrocytes and the rate of longitudinal bone growth in growth plates. J Orthop Res 1991; 9: 348-59.

[34] Abad V, Uyeda JA, Temple HT, De Luca F, Baron J. Determinants of spatial polarity in the growth plate. Endocrinology 1999; 140: 958-62.

[35] Abad V, Meyers JL, Weise M, et al. The role of the resting zone in growth plate chondrogenesis. Endocrinology 2002; 143: 18511857.

[36] Moore WJ, Lavelle CLB. Growth of the facial skeleton in the hominoidea, London: Academic Press 1974.

[37] Lieberman DE, Pearson OM, Mowbray KM. Basicranial influence on overall cranial shape. J Human Evolut 2000a; 38: 291-315.

[38] Lieberman DE, Ross CF, Ravosa MJ. The primate cranial base: ontogeny, function, and integration. Am J Phy Anthrop 2000b; Suppl 31: 117-69.

[39] Biegert J. The evaluation of characters of the skull, hands and feet for primate taxonomy. In: Classification and Human Evolution. Washburn SL, Ed. Chicago: Aldine 1963; pp. 116-45.

[40] Enlow DH. The human face: an account of the postnatal growth and development of the craniofacial skeleton. New York: Harper and Row 1968.

[41] Moss ML, Young RW. A functional approach to craniology. Am J Phys Anthropol 1960; 18: 281-92.

[42] Thorogood P. The developmental specification of the vertebrate skull. Cambridge: The Company of Biologist 1988; vol. 103(Suppl): pp. 141-53.

[43] Dixon AD, Gakunga PT. Morphometric changes in growth of the rat pelvis after papain administration. Anat Rec1993; 235: 312-8.

[44] Baume LJ. Principles of cephalofacial development revealed by experimental biology. Am J Orthod 1961; 47: 881.

[45] Kember NF, Kirkwood JK. Cell kinetics and the study of the longitudional bone growth:a perspective. In: Dixon AD, Sarnat BG, Hoyte DAN, Eds. Fundamentals of bone growth: methodology and applications. Boca Raton: CRC Press 1991; pp. 153-62.

[46] Cobourne MT. Construction for the modern head: current concepts in craniofacial development. J Orthod 2000; 27: 307-14.

[47] Nemzek WR, Brodie HA, Hecht ST, Chong BW, Babcook CJ, Seibert JA. MR, CT, and plain film imaging of the developing skull base in fetal specimens. AJNR: Am J Neuroradiol 2000; 21: 1699706.

[48] Moss-Salentijn L. Cartilage canals in the human spheno-occipital synchondrosis during fetal life. Acta Anat 1975; 92: 595-606.

[49] Dorenbos J. Morphogenesis of the spheno-occipital and the presphenoidal synchondrosis in the cranial base of the fetal Wistar rat. Acta Morphol Neerlando Scand 1973; 11: 63-74

[50] Roberts GJ, Blackwood HJ. Growth of the cartilages of the midline cranial base : a radiographic and histological studies. J Anat 1983; 136: 307.
[51] Shum L, Wang X, Kane AA, Nuckolls GH. BMP4 promotes chondrocyte proliferation and hypertrophy in the endochondral cranial base. Int J Dev Biol 2003; 47: 423-31.

[52] Hoyte DA. A critical analysis of the growth in length of the cranial base. Birth Defects Orig Artic Ser 1975; 11: 255-82.

[53] Latham RA. The sella point and postnatal growth of the human cranial base. Am J Orthod 1972; 61: 156-62.

[54] Enlow DH. The Human Face: an Account of the Postnatal Growth and Development of the Craniofacial Skeleton. New York: Harper and Row 1968.

[55] Melsen B. Time and mode of closure of the spheno-occipital synchondrosis determined on human autopsy material. Acta Anat 1972; 83: 112 .

[56] Hoyte D. Alizarin red in the study of the opposition and resorption of bone. Am J Phys Anthrop 1968; 29: 157.

[57] Vilmann $\mathrm{H}$. The growth of the cranial base in the Wistar albino rat studied by vital staining with alizarin red S. Acta Odont Scand Sup 1971; 29: 1-44

[58] Scott JH. Dentofacial development and growth. Oxford: Pergamon Press 1967.

[59] Moss ML. New research objectives in craniofacial morphogenesis. Acta Morphol Neerlando Scand 1972; 10: 103-10.

[60] Moss ML. The functional matrix hypothesis revisited. 1. The role of mechanotransduction. Am J Orthod Dentofac Orthop 1997; 112: 8-11.

[61] Petrovic A, Charlier JP. La synchondrose spheno-occipitale de jeune rat en culture d'organes: mise en evidence d'un potential de croissance independent. C R Acad Sci 1967; 265: 1511.

[62] Servoss JM. An in vivo and in vitro autoradiographic investigation of growth in synchondrosal cartilages. Am J Anat 1973; 136: 479

[63] Kuroda T, Miura F, Nakamura T, Noguchi K. Cellular kinetics of synchondrosal cartilage in organ culture. Proc Finn Dent Soc 1981; 77: 89

[64] Peltomaki T, Kylamarkula S, Vinkka-Puhakka H, Rintala M, Kantomaa T, Ronning O. Tissue-separating capacity of growth cartilages. Eur J Orthod 1997; 19: 473-81.

[65] Ronning O, Kylamarkula S. Morphogenetic potential of rat growth cartilages as isogeneic transplants in the interparietal suture area. Arch Oral Biol 1982; 27: 581-8.

[66] Kantomaa T, Pirttiniemi P, Tuominen M. Cranial base and the growth of the cranial vault: an experimental study on the rabbit. Proc Finn Dent Soc 1991; 87:93-8.

[67] Jeffery N. A high-resolution MRI study of linear growth of the human fetal skull base. Neuroradiology 2002; 44: 358-66.

[68] Jeffery N, Spoor F. Ossification and midline shape changes of the human fetal cranial base. Am J Phys Anthropol 2004; 123: 78-90.

[69] Ford EHR. Growth of the human cranial base. Am J Orthod 1958; 44: 498.

[70] Irwin GL. Roentgen determination of the time of closure of the spheno-occipital synchondrosis. Radiology 1960; 75:450.

[71] Powell TV, Brodie AG. Closure of the spheno-occipital synchondrosis. Anat Rec 1963; 147:15.

[72] Madeline LA, Elster AD. Suture closure in the human chondrocranium: CT assessment. Radiology 1995; 196: 747-56.

[73] Latham RA. The sella point and postnatal growth of the human cranial base. Am J Orthod 1972; 61:156

[74] Enlow DH. Facial growth. $3^{\text {rd }}$ ed. Philadelphia: WB Saunders 1990

[75] Lieberman DE. How and why recent humans grow thin skulls: experimental data on systemic cortical robusticity. Am J Phys Anthropol 1996; 101: 217-36.

[76] Farkas LG, Posnick JC, Hreczko TM. Anthropometric growth study of the head. Cleft Palate Craniofac J 1992; 29: 303-18.

[77] Sperber GH. Craniofacial Embryology. $4^{\text {th }}$ ed. London: Wright 1989.

[78] Laitman JT, Crelin EJ. Postnatal developmentof the basicranium and vocal tract region in man. In: Bosma JF, Ed. Symposium on development of the basicranium. Bethesda: Department of Health, Education and Welfare 1976.

[79] Silverman FN. Some features of developmental changes observed clinically in the sphenoid and basicranium. In: Bosma JF, Ed. Symposium on development of the basicranium. Bethesda: Department of Health and Welfare 1976; pp. 319-45.

[80] Enlow DH. The prenatal and postnatal growth of the human basicranium in Symposium on Development of the Basicranium. Bosma JF, Ed., DHEW Publ. No. (NIH) 76-989, NIH Bethesda $1976 ; 192-205$ 
[81] Plavcan JM, German RZ. Quantitative evaluation of craniofacial growth in the third trimester human. Cleft Palate Craniofac J 1995; 32: 394-404.

[82] Koop M, Rilling G, Herrmann A, Kretschmann HJ. Volumetric development of the fetal telencephalon, cerebral cortex, diencephalon, and rhombencephalon including the cerebellum in man. Bibliotheca Anat 1986: 53-78.

[83] Ross CF, Ravosa MJ. Basicranial flexion, relative brain size, and facial kyphosis in nonhuman primates. Am J Phy Anthrop 1993; 91: 305-24.

[84] Ross CF, Henneberg M, Ravosa MJ, Richard S. Curvilinear, geometric and phylogenetic modeling of basicranial flexion: is it adaptive, is it constrained? J Hum Evolut 2004; 46: 185-213.

[85] Ford E. The growth of the foetal skull. J Anat 1956; 90: 63

[86] Diewert VM, Maeda S, Lozanoff S. In: Analysis of human fetal craniofacial growth between 12 and 20 weeks with finite element modelling (FEM). Dixon AD, Sarnat BG, Hoyte DAN, Eds. Fundamentals of Bone Growth :Methodology and Applications. Boca Raton: CRC Press 1991; pp. 565-78.

[87] George SL. A longitudinal and cross-sectional analysis of the growth of the postnatal cranial base angle. Am J Phy Anthrop 1978; 49: 171-8.

[88] Lewis AB, Roche AF. The saddle angle: constancy or change? Angle Orthod 1977; 47: 46.

[89] Andria LM, Leite LP, Prevatte TM, King LB. Correlation of the cranial base angle and its components with other dental skeletal variables and treatment time. Angle Orthod 2004; 74: 361-6.

[90] Ranly DM. A synopsis of craniofacial growth, $2^{\text {nd }}$ ed. Connecticcut: Appleton and Lange 1988.

[91] Klocke A, Nanda RS, Kahl-Nieke B. Role of cranial base flexure in developing sagittal jaw discrepancies. Am J Orthod Dentofac Orthop 2002; 122: 386-91.

[92] Hopkin GB, Houston WJ, James GA. The cranial base as an aetiological factor in malocclusion. Angle Orthod 1968; 38: 250-5.

[93] Scott JH. Dentofacial Development and Growth. Oxford: Pergamon Press 1967.

[94] Bacon W, Eiller V, Hildwein M, Dubois G. The cranial base in subjects with dental and skeletal class II. Eur J Orthod 1992; 14:224-8.

[95] Kerr WJS. A method of superimposing lateral cephalometric films for the purpose of comparison: a preliminary report. Br J Orthod 1978; 5: 51-3.

[96] Houston WJ. A cephalometric analysis of Angle class II, division II malocclusion in the mixed dentition. Dent Pract Dent Rec1967; 17: 372-6.

[97] James GA. Cephalometric analysis of 100 class II div 1 malocclusions with special reference to the cranial base. Dent Pract 1962; 14: 35-46.

[98] Enlow DH, Hans MG. Essentials of Facial Growth. Philadelphia: WB Saunders 1996.

[99] Dhopatkar A, Bhatia S, Rock P. An investigation into the relationship between the cranial base angle and malocclusion. Angle Orthod 2002; 72: 456-63.
[100] Singh GD. Morphologic determinants in the etiology of class III malocclusions: a review. Clin Anat 1999; 12: 382-405.

[101] Axelsson S, Kjaer I, Bjornland T, Storhaug K. Longitudinal cephalometric standards for the neurocranium in Norwegians from 6 to 21 years of age. Eur J Orthod 2003; 25: 185-98.

[102] Anderson D, Popovich F. Correlations among craniofacial angles and dimensions in class I and class II malocclusions. Angle Orthod 1989; 59: 37-42.

[103] Kreiborg S, Marsh JL, Cohen JMM. Comparative threedimensional analysis of CT-scans of the calvaria and cranial base in Apert and Crouzon syndromes. J Cran Maxillofac Surg 1993; 21: 181.

[104] Brkic H, Kaic Z, Poje Z, Singer Z. Shape of the craniofacial complex in patients with Klinefelter syndrome. Ang Orthod 1994; 64: 371-6.

[105] Mass E, Belostoky L. Craniofacial morphology of children with Williams syndrome. Cleft Palate-Craniofac 1993; 30: 343-9.

[106] Midtbo M, Wisth PJ, Halse A. Craniofacial morphology in young patients with Turner syndrome. Eur J Orthod 1996; 18: 215-25.

[107] Quintanilla JS, Biedma BM, Rodriguez MQ, Mora MT, Cunqueiro MM, Pazos MA. Cephalometrics in children with Down's syndrome. Pediatr Radiol 2002; 32: 635-43.

[108] Harris EF. Size and form of the cranial base in isolated cleft lip and palate. Cleft Palate-Craniofac J 1993; 30: 170-4

[109] Molsted K, Kjaer I, Dahl E. Spheno-occipital synchondrosis in three-month-old children with clefts of the lip and palate: a radiographic study. Cleft Palate-Craniofac J 1993; 30: 569-73.

[110] Lefebvre V, Smits P. Transcriptional control of chondrocyte fate and differentiation. Birth Defects Res Part C Embryo Today Rev 2005; 75: 200-12.

[111] Foster JW. Mutations in SOX9 cause both autosomal sex reversal and campomelic dysplasia. Acta Paediatr Jap 1996; 38: 405-11.

[112] Yamashiro T, Wang XP, Li Z, et al. Possible roles of Runx1 and Sox9 in incipient intramembranous ossification. J Bone Min Res 2004; 19: 1671-7.

[113] Rice DP, Rice DPC. Craniofacial anomalies: from development to molecular pathogenesis. Cur Mol Med 2005; 5: 699-722.

[114] Schell-Apacik C, Rivero M, Knepper JL, Roessler E, Muenke M, Ming JE. SONIC HEDGEHOG mutations causing human holoprosencephaly impair neural patterning activity. Hum Genet 2003; 113: 170-7.

[115] Cendekiawan T, Wong RWK, Rabie ABM. Temporal Expression of SOX9 and Type II Collagen in Spheno-Occipital Synchondrosis of Mice after Mechanical Tension Stimuli. Angle Orthod 2008; 78(1): 83-88

[116] Lei SWL, Wong RWK, Rabie ABM. Factors regulating endochondral ossification in the spheno-occipital synchondrosis. Angle Orthod 2008; 78(2): 215-20.

[117] Rukkulchon BK, Wong RWK. Effect of tensile force on expression of PTHrP and thickness of hypertrophic zone in organ-cultured mouse spheno-occipital synchondroses. Arch Oral Biol 2008; 53: 690-9. 